Tohoku J. Exp. Med., 2005, 207, 133-142

\title{
Interleukin-10 Gene Therapy Attenuates Pulmonary Tissue Injury Caused by Mesenteric Ischemia- Reperfusion in a Mouse Model
}

\author{
Burhan Kabay, Faruk O. Aytekin, Cagatay Aydin, Atilla Ozer, ${ }^{1}$ \\ Nilgun Kabay, ${ }^{2}$ Koray Tekin, Ugur Sungurtekin, Ergun Erdem \\ and AKIN OzDEN
}

Department of General Surgery, ${ }^{1}$ Department of Surgery, Pamukkale University Faculty of Medicine, and ${ }^{2}$ Department of Chemistry, Pamukkale University

Faculty of Sciences-Art, Denizli, Turkey

\begin{abstract}
Kabay, B., Aytekin, F.O., Aydin, C., Ozer, A., Kabay, N., Tekin, K., Sungurtekin, U., ERdem, E. and Ozden, A. Interleukin-10 Gene Therapy Attenuates Pulmonary Tissue Injury Caused by Mesenteric Ischemia-Reperfusion in a Mouse Model. Tohoku J. Exp. Med., 2005, 207 (2), 133-142 — To investigate the role of interleukin (IL)-10 gene therapy on the reperfusion-induced lung injury, we utilised the technique of liposomal gene delivery before the induction of intestinal ischemia. Plasmid DNA encoding human IL10 (hIL-10) or empy vector was injected intraperitoneally $24 \mathrm{~h}$ before the study. Male Balb/c mice randomized into three groups: Sham operated control $(n=12)$, empty plasmid vector $(n=$ $12)$, and hIL-10 gene therapy group $(n=12)$. The ischemia was generated by selective occlusion of superior mesenteric artery for $60 \mathrm{~min}$ and followed by reperfusion for 30 min. Lung tissue neutrophil infiltration was determined by myeloperoxidase assay and neutrophil counts. For the determination of lung tissue microvascular permeability, Evans blue dye injection was made and the lung edema was assesed by wet/dry ratio. hIL-10 protein expression was studied by immunostaining and ELISA. We found that pre-ischemic hIL-10 overexpression attenuated dye extravasation, leukocyte sequestration and reduced pulmonary tissue injury compared to the empty vector-injected control. Our study indicates that pre-ischemic hIL-10 overexpression attenuates lung injury caused by intestinal ischemia-reperfusion. — intestinal ischemia; reperfusion; lung injury; interleukine-10; gene therapy
\end{abstract}

(C) 2005 Tohoku University Medical Press

A period of acute ischemia followed by restoration of blood flow may produce a diffuse and potentially life-threatening systemic inflammatory response, in which pulmonary injury is the most pertinent manifestation (McMillen et al. 1993; Sisley et al. 1994; Aytekin et al. 2005). A com- plex group of factors such as cytokines, complement components, oxygen-free radicals, activated neutrophils and many others are believed to have a role in the development of the ischemia-reperfusion (I/R) induced pulmonary injury (Koike et al. 1994; Kuzu et al. 2002). Although the exact

Received May 2, 2005; revision accepted for publication July 23, 2005.

Turkey.

Correspondence: Burhan Kabay, M.D., Tekinevler Sitesi A4 Blok 23. sk.Kat:6 D:19, Yenisehir Denizli,

e-mail: bkabay@pamukkale.edu.tr 
mechanisms that initiate progression to end-organ injury are not clearly defined, harmful effects of activated neutrophils are implicated in increased pulmonary capillary permeability (Schmelling et al. 1989; Lucchesi 1994; Abraham 2003; de Perrot 2003).

Interleukin (IL)-10 is a Th-2 cytokine that mediates and regulates immune and inflammatory responses. It has a complex role in I/R injury and possesses multiple properties. IL-10 is involved in lymphoid and myeloid cell development, and activation (Moore 2001). The inhibition of inflammatory cell migration and the suppression of the expression of proinflammatory cytokines by recruited macrophages, such as tumor necrosis factor- $\alpha$ and IL- $1 \beta$ are blocked by recombinant IL-10 (rIL-10) (Fiorentino et al. 1991). In experimental I/R injury models, rIL-10 attenuates heart, intestine, liver and hindlimb injury, and ameliorates acute lung injury secondary to liver, lung, hindlimb or intestinal ischemia (Engles et al. 1997; Lane et al. 1997; Yoshidome et al. 1999; Yang et al. 2000). The proposed mechanism by which rIL-10 shows its actions is through reduction of neutrophil recruitment and the suppression of serum tumor necrosis factor (TNF)- $\alpha$, thus reducing the severity of local and systemic inflammation. Owing to these potent negative regulations of immune responses, IL-10 has been suggested as a beneficial cytokine for immune modulation.

Locally produced cytokines exist at concentrations several hundred times higher at the site of inflammation than in the blood (Ogawa 1996). Modulation of this cytokine milieu by exogenous administration of rIL-10 is hindered by the short biological half-life of the protein and by the limited access to tissue intersitisium. Consequently, giving the rIL-10 exogenously does not maintain high tissue levels of protein. Therefore continuous administration of IL-10 protein is needed to maintain biologically active concentrations, which makes recombinant protein usage impractical on a clinical basis (Li et al. 1994; Chernoff et al. 1995). For this reason alternative means of treatment strategies are currently under search, and strategy of gene delivery represents an alternative.
Gene transfer technology now permits directed expression of exogenous genes within organs of intact animals and, this technology offers both localized and systemic biological effect for extended periods of time. But practical means of achieving this are yet to be perfected. In experimental studies gene therapy has been applied to treat acute and chronic inflammatory processes and is considered to have a promising future (Barbara et al. 2000; Morrison et al. 2000; Takakuwa et al. 2000).

In this paper, we utilized systemic liposomal delivery of plasmid DNA to study the effect of human IL-10 (hIL-10) on pulmonary tissue secondary to I/R produced by superior mesenteric artery occlusion.

\section{Materials and Methods}

Surgical procedure and experimental design

The study was performed with male Balb/c mice weighing between $25-35 \mathrm{~g}$. The animals were housed in wire-bottom cages at $24^{\circ} \mathrm{C}$ room temperature with a 12 hour light-dark cycle and were fed standard rat chow and water for $12 \mathrm{~h}$ before surgery. The use of anesthesia during the operative procedure and subsequent postoperative care were consistent with the guidelines in the National Institute of Health's Guide for the care and use of laboratory animals (NIH publication No. 86-23, revised 1985, Bethesda, MD, USA). Approval of the Animal Use Committee of the Pamukkale University was obtained before initiating the experiments.

All animals were fasted overnight and anesthetized by and intramuscular injection of ketamine $50 \mathrm{mg} / \mathrm{kg}$ (Ketalar; Parke Davis, Eczacıbaşı, İstanbul, Turkey) and xylazine $10 \mathrm{mg} / \mathrm{kg}$ (Rompun; Bayer AG, Leverkusen, Germany). A heating pad and a heating lamp were used to keep the animals warm. Ringer's lactated solution (2 $\mathrm{ml}$ ) was given subcutaneously to prevent dehydration of the mice. A midline abdominal incision was performed to expose superior mesenteric artery (SMA) and the mice were divided into three groups. In sham operated group $(n=12)$, the SMA and collateral branches dissected from the celiac axis and the inferior mesenteric artery were isolated but not occluded, then abdominal incision was closed and animals were followed $90 \mathrm{~min}$ to simulate the ischemia-reperfusion interval in the other groups. In plasmid vector-given group $(n=12)$, the SMA was isolated, and ischemia was induced by totally occluding the 


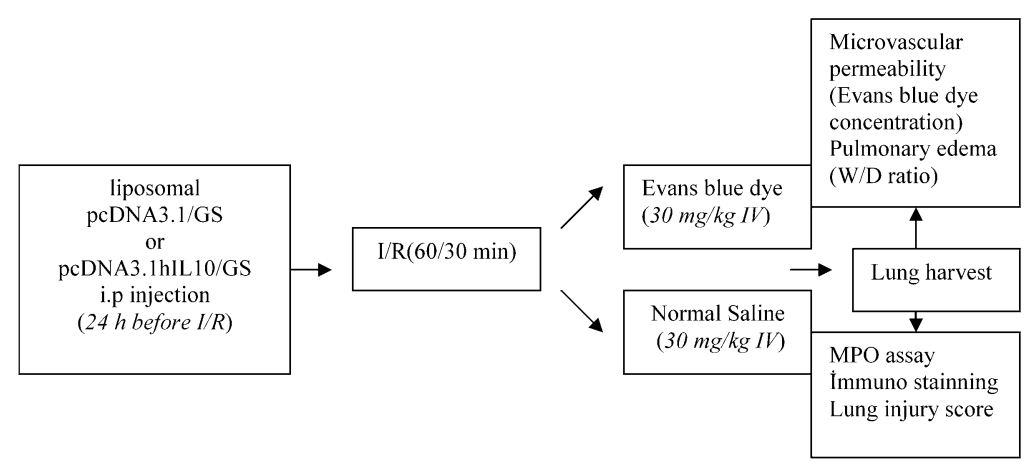

Fig. 1. Experimental protocol used to examine the effects of intestinal ischemia and reperfusion on pulmonary neutrophil acumulation and microvascular permeability.

SMA for 60 min. By this procedure, the terminal ileum, cecum, and right colon were rendered ischemic. Twenthyfour hours before surgical procedures, animals received liposomal $100 \mu \mathrm{g}$ empty plasmid DNA (pcDNA3.1/GS) or hIL-10 carrying plasmid DNA (pcDNA3.1hIL-10/GS) intraperitoneally. Mesenteric ischemia was confirmed when the mesenteric pulsation was lost and intestines became pale. Reperfusion was confirmed by the return of pulsatile blood flow at the mesenteric vessels in the intestines that were directly subjected to the I/R injury following declamping. For the biochemical and histopathological analyses, reperfusion was allowed to occur for $30 \mathrm{~min}$, and then mice were sacrificed. This time of reperfusion (30 $\mathrm{min})$ was chosen based on the presence of significant tissue injury without unduly high mortality rates (Fig. 1).

\section{Effects of intestinal I/R on mortality}

A laparotomy was performed, and intestinal ischemia was induced by occluding the SMA with a microbulldog clamp (World Precision Instruments Inc., Sarasola, FL, USA). Satisfactory occlusion was confirmed by the absence of mesenteric pulsation and intestinal pallor. The abdomen was covered with warm moist gauze during this period. Control mice underwent a sham operation in which the superior mesenteric artery was exposed but not occluded. For measuring percentage of surviving mice, reperfusion was re-established after $60 \mathrm{~min}$ of ischemia, and mice were monitored for 120 $\min$.

\section{Pulmonary edema}

At the end of reperfusion, a median sternotomy was performed and animals were killed by cutting ascending aorta. After the lungs were removed from the thoracic cavity, inferior third of the reperfused left lung were weighed and then placed in a drying oven at $90^{\circ} \mathrm{C}$ for $24 \mathrm{~h}$. After this drying procedure the specimen was reweighed, and the ratio of the weight before and after drying was calculated. Lung edema is represented by an increase in this ratio.

\section{Pulmonary microvascular permeability analysis}

Pulmonary vascular permeability was estimated by using the Evans Blue method. Evans blue dye, which strongly binds to albumin, is a well-known marker of protein extravasation in models of acute lung injury (Sakuma et al. 2001). In present study, only half of the mice $(n=6)$ of each group was injected Evans blue (30 $\mathrm{mg} / \mathrm{kg}$ ) into the penile vein just before declamping the SMA, because it was impossible to perform simultaneous biochemical and the Evans blue dye measurements in the same animals by using photometric method. At the end of reperfusion, the right lung was perfused via the pulmonary artery for $2 \mathrm{~min}$ with saline $\left(37^{\circ} \mathrm{C}\right)$ at 0.04 $\mathrm{ml}$ per $\mathrm{g}$ body-weight per min using an infusion pump (Vial medical-program 1, Beckton Dickinson, France) to eliminate residual blood and Evans blue dye from the pulmonary bed as described previously (Koksoy et al. 2000). Following infusion, the right lung was excised, rinsed externally with saline and then placed in a drying oven at $90^{\circ} \mathrm{C}$ for $24 \mathrm{~h}$. Dried tissue samples were placed in $2 \mathrm{ml}$ of formamide at $37^{\circ} \mathrm{C}$ for $24 \mathrm{~h}$. The dye concentration of the samples was then measured by spectrophotometry at $620 \mathrm{~nm}$.

\section{Histopathologic examination}

Immediately after the animals were killed, the upper third of the left lung was fixed in $10 \%$ formalin solution. Paraffin-embedded sections (4- $\mu \mathrm{m}$, haemotoxylin \& eo- 
sin stained) were examined under a light microscope. Pulmonary tissue neutrophil sequestration was determined according to the method described by Koksoy et al. (2001). A single pathologist blinded to the groups examined at least two different sections of each specimen. Alveolar septal wall neutrophil sequestration in the peripheral lung parenchyma was expressed as the mean number of neutrophils per 10 high-power fields $(\times 400)$. Severity of lung injury was scored as described previously (Nishina et al. 1997). Lung injury was scored by a blinded pathologist using a 5-point scale according to combined assessments of alveolar congestion, hemorrhage, infiltration or aggregation of neutrophils in the airspace or vessel wall, and thickness of alveolar wall/ hyaline membrane formation: $0=$ minimum damage, $1+$ $=$ mild damage, $2+=$ moderate damage, $3+=$ severe damage, and $4+=$ maximum damage.

\section{Pulmonary myeloperoxidase (MPO) activity}

Lung tissue MPO activity was determined by the method of Koike et al. (1994). Lung tissue was homogenized in $20 \mathrm{mM}$ potassium phosphate buffer ( $\mathrm{pH}: 7.4$ ) and the homogenate was centrifuged for $5 \mathrm{~min}$ at 10,000 $\mathrm{xg}$ at $4^{\circ} \mathrm{C}$. The supernatant was discarded, and the pellet was resuspended in $50 \mathrm{mM}$ potassium phosphate buffer (pH: 6.0) containing $0.5 \%$ hexadecyltrimethylammonium bromide (HTAB) and frozen at $-70^{\circ} \mathrm{C}$. Before assay, batched samples were thawed, sonicated for 10 seconds, incubated for 2 hour in a water bath $\left(60^{\circ} \mathrm{C}\right)$, and then centrifuged at 10,000 $\mathrm{xg}$ for $5 \mathrm{~min}$. The supernatants were used for MPO assay. MPO activity was assessed by measuring the $\mathrm{H}_{2} \mathrm{O}_{2}$-dependent oxidation of o-dianisidin. One unit of enzyme activity was defined as the amount of MPO present that caused a change in absorbance of $1.0 / \mathrm{min}$ at $410 \mathrm{~nm}\left(37^{\circ} \mathrm{C}\right)$.

\section{Plasmid vectors and cationic liposom/DNA preparation}

Plasmid DNA transferred into GeneHogs ${ }^{\circledR}$ E. coli encoding for hIL-10 (pcDNA3.1hIL10/GS), and empty control vector (pcDNA3.1/GS) obtained from Research Genetics Co., Huntsville, AL, USA. pcDNA3.1hIL10/GS vector contains an expression cassette consisting of the cytomegalovirus (CMV) immediate early promoter and enhancer followed by bovine growth hormone and SV40 polyadenylation signal. hIL-10 gene is fused to a C-terminal peptide encoding the V5 epitope for detection with the anti-V5-HRP antibody, which is supplied by the manufacturer. The vector also encodes the bleomycin resistance gene for selection in E. coli. Plasmid DNA was isolated and endotoxin removed using the Gene Elute endotoxin-free Plasmid Midiprep Kit (Sigma-Aldrich Inc., St Louis, MO, USA). pcDNA3.1/GS, which was used as control vector contains an expression cassette consisting of the CMV immediate early promoter and SV40 polyadenylation signal followed by bleomycin resistance gene for selection in E. coli.

In vivo Lipozom Transfection Reagent $(20 \mathrm{mM}$ DOTAP: Cholesterol [1:1 molar ratio] extruded liposomes in $\% 5$ glucose, Sigma-Aldrich Inc., St Louis, MO, USA) was used to transfer plasmid DNA as described by the manufacturer. Preliminary calibration mixing tests performed to determine the appropriate amounts of DNA and liposomes that give complexes suitable for injection. The quality of liposome/DNA complexes was determined by the $\mathrm{A}_{400}$ values of the mixture. $\mathrm{A}_{400}$ of 0.5-0.9 for a $1: 20$ dilution in water indicates that the mixture is suitable for in vivo studies.

\section{Detection of IL-10 protein}

For immunostainnig of hIL-10 protein on tissue sections, $4 \mu \mathrm{m}$ cryostat sections of $10 \%$ buffered formalin fixed tissues were deparafinised/rehydrated and then labeled with the primary monoclonal antibody, anti-V5HRP. Enzyme conjugated secondary antibodies; biotynylated anti-mouse IgG and streptavidin-HRP were applied (DAKO, LSAB ${ }^{\circledR} 2$ System, Denmark). Following the secondary antibody incubation, sections were quenched for endogenous peroxidase activity and blocked for non-specific binding interactions for 1 hour using an albumin based blocking solution. Chromogenic staining was performed with 3,3-diaminobezidine to produce a brown color. Sections were counterstained with Harris' hematoxylin. Transgene expression was also studied by using a hIL-10 protein ELISA testing of the animals. Plasma hIL-10 level was assessed by a sandwich ELISA using commercial human IL-10 ELISA kits (Roche Diagnostics GmbH, Mannheim, Germany).

\section{Statistical analysis}

The data on lung injury score are given as median (range), whereas the other data are expressed as mean \pm S.E.M. Differences were evaluated by using ANOVA followed by the Student-Newman-Keul's post hoc analysis. The lung injury scores were analyzed using the KruskallWallis rank test. $P<0.05$ was accepted as significant. For the survival analyses, the differences were evaluated by the Kaplan-Meier analysis. Results were considered to be of statistical significance when the $p<0.05$. Data 
were analyzed by statistical software (SPSS for Windows 10.0; SPSS, Chicago, IL, USA).

\section{Results \\ Expression of hIL-10 protein}

Following administration of the human hIL-10 plasmid pcDNAhIL103.1/GS complexed with 20 mM DOTAP: Cholesterol liposomes, efficient in vivo gene transfer was detected. Fig. 2 demonstrates the photomicrographs of hIL-10 immunostained lung tissue sections. Fig. 2A demonstrates hIL-10 protein expression within alveolar type-1 cells. Vascular endothelial and perivascular immunostaining was shown in Fig. 2B. Non-staining in control mice was given in Fig. 2C.

The plasma concentrations in the nontreated mice were below the limit of detection $(<15 \mathrm{pg} /$ $\mathrm{ml})$. The plasma hIL-10 concentrations in the mice injected with liposomal hIL-10 plasmid DNA were increased $12.8 \pm 1.28 \mathrm{ng} / \mathrm{ml}$ at sacrifice.

\section{Pulmonary edema and permeability analysis}

There were statistically significant differences among the groups in terms of lung tissue wet/ dry ratio $\left(\chi^{2}=28.98,2\right.$ d.f., $\left.p=0.001\right)$. Animals having empty vector demonstrated a significant increase in lung tissue dry/wet ratio compared to sham group $(7.47 \pm 0.35$ vs $3.83 \pm 0.70, p=$ $0.0001)$. hIL-10 gene therapy displayed significant attenuation of the pulmonary edema (4.26 \pm $0.47, p=0.0001)$, but this improvement did not reach the control levels $(p=0.0001)$ (Fig. 3).

Extravasation of Evans blue dye was significantly higher in empty vector group compared to sham group $(171.56 \pm 6.47$ vs $37.8 \pm 1.96, p=$ $0.002)$. hIL-10 gene transfer significantly reduced extravasation of Evans blue dye in the pulmonary tissue $(56.18 \pm 4.81)$, but this reduction was not enough to reach that of sham operated animals $(p=0.01)$ (Fig. 4).

\section{Pulmonary neutrophil sequestration and MPO analysis}

Differences among the groups in terms of neutrophil sequestration were statistically
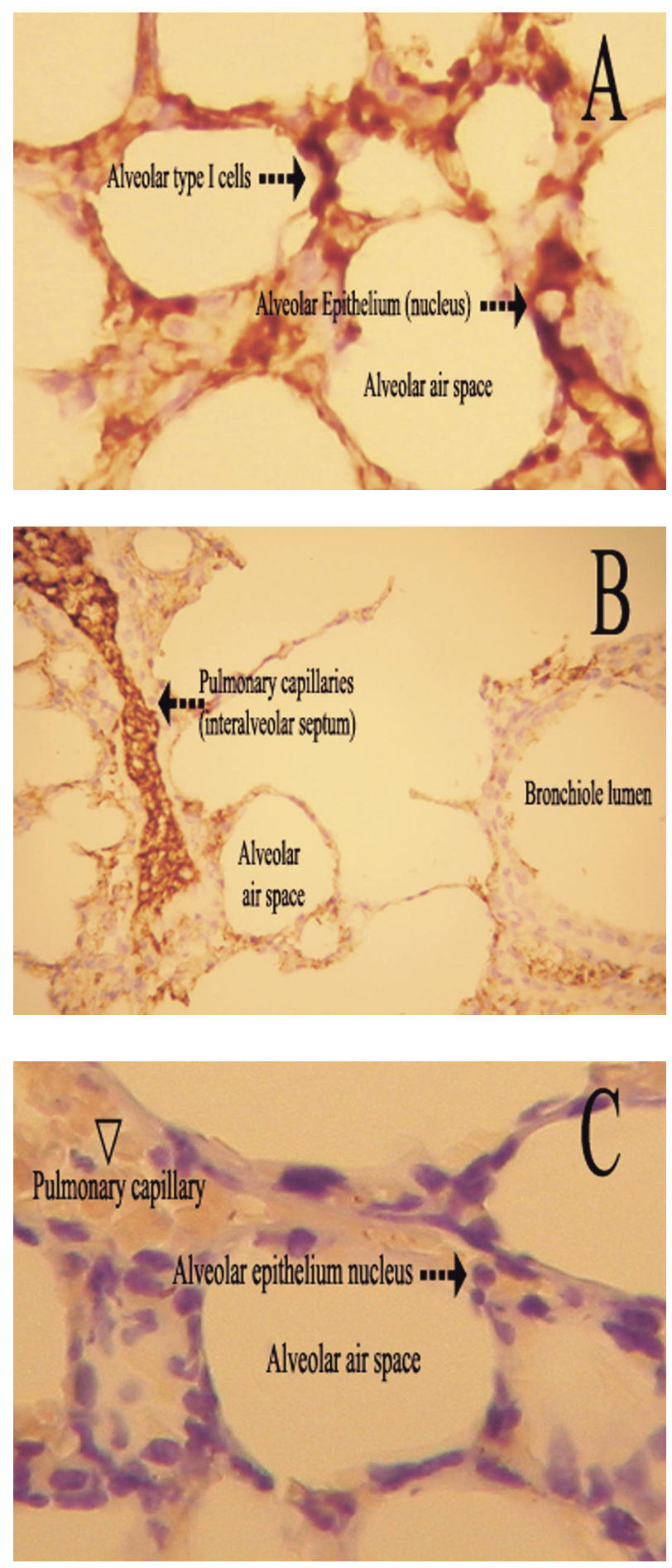

Fig. 2. Cytoplasmic immunostainning with antiV5HRP antiboy in the lung parenchyma. hIL-10 expression in the (A) cytoplasma of alveolar type-1 cells, (B) Vascular endothelium and perivascular area, (C) nonstained control. (Biotin streptavidin peroxidase-DAB, original magnification $\times 400$ ). 


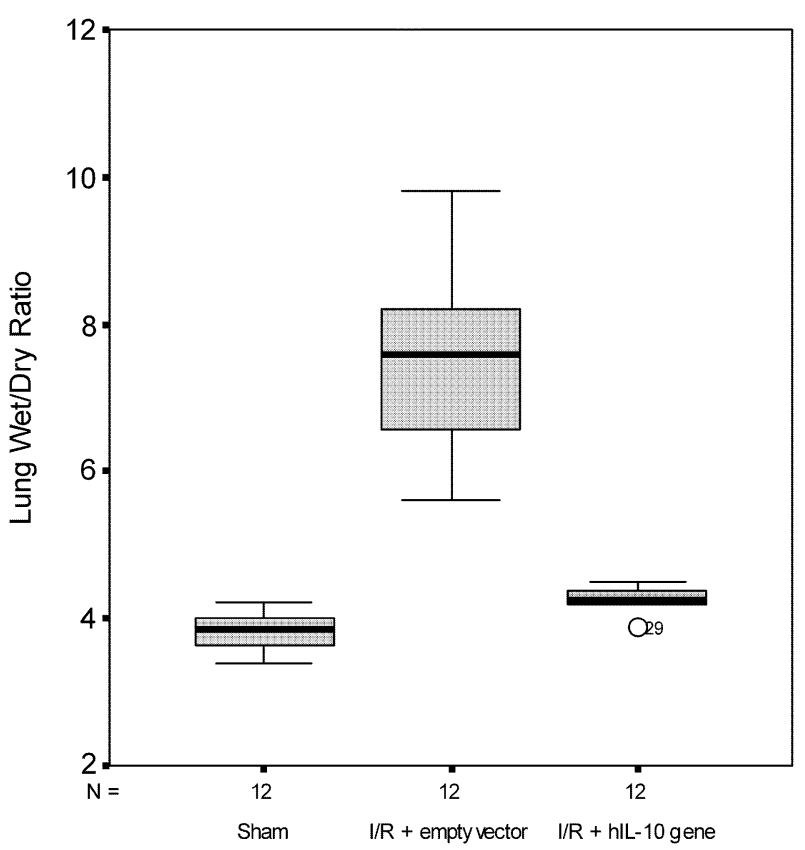

Fig. 3. Lung tissue wet/dry ratio in groups. Lung tissue wet/dry ratio was significantly lower in hIL-10 gene therapy group compared to empty plasmid DNA transferred group ( $p=0.0001)$.

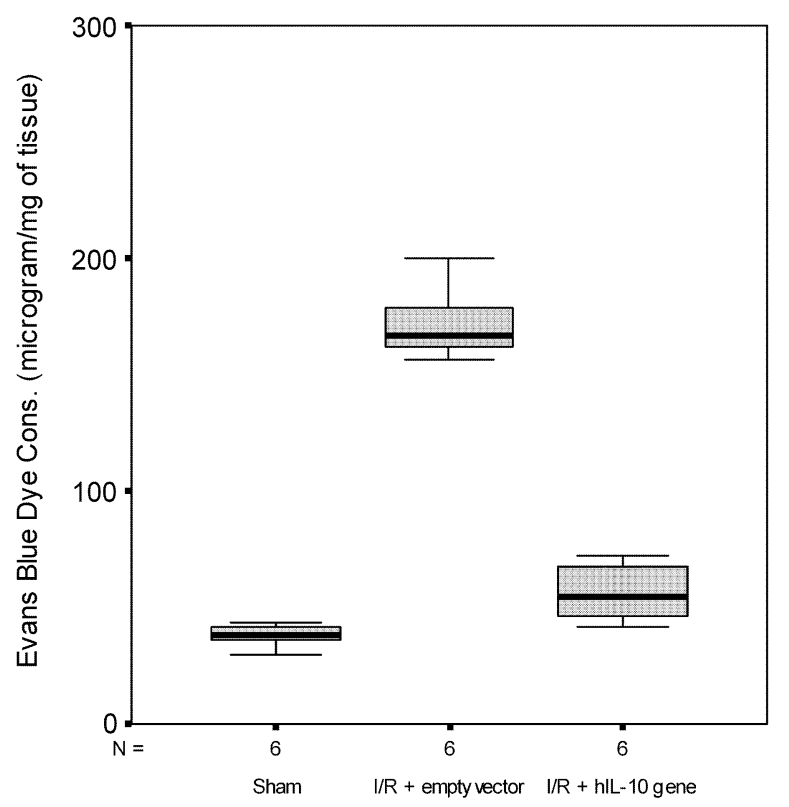

Fig. 4. Lung tissue Evans blue dye concentration in groups. Evans blue dye concentration was significantly lower in hIL-10 gene therapy group compared to empty plasmid DNA transferred group $(p=0.01)$.

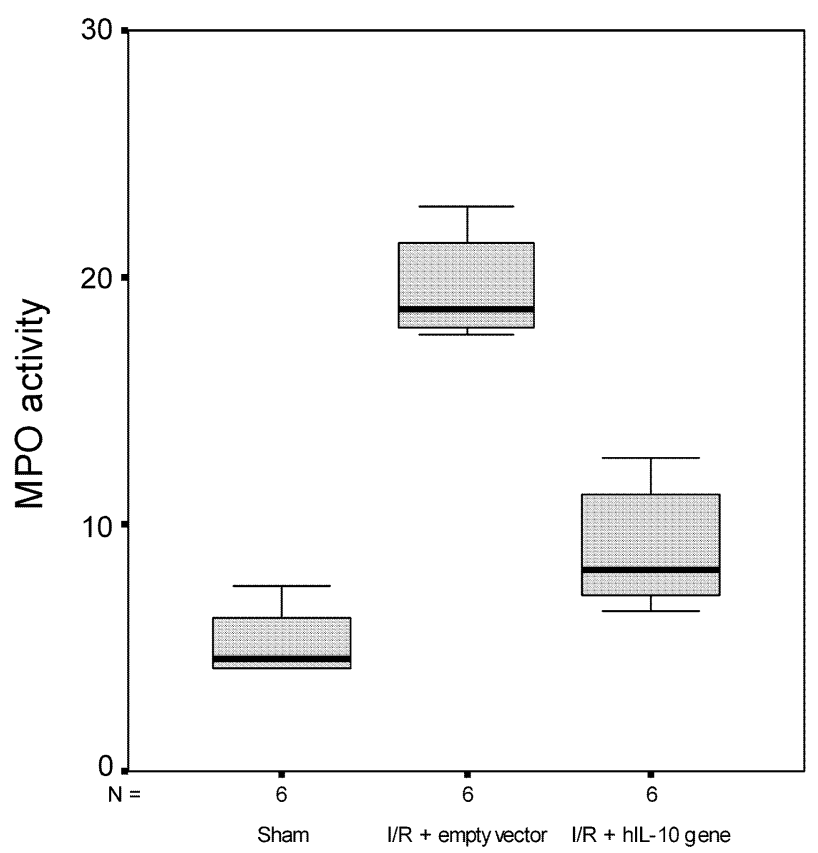

Fig. 5. Lung tissue MPO activity in groups. Lung tissue MPO activity was significantly lower in hIL-10 gene therapy group compared to empty plasmid DNA transferred group $(p=0.002)$.

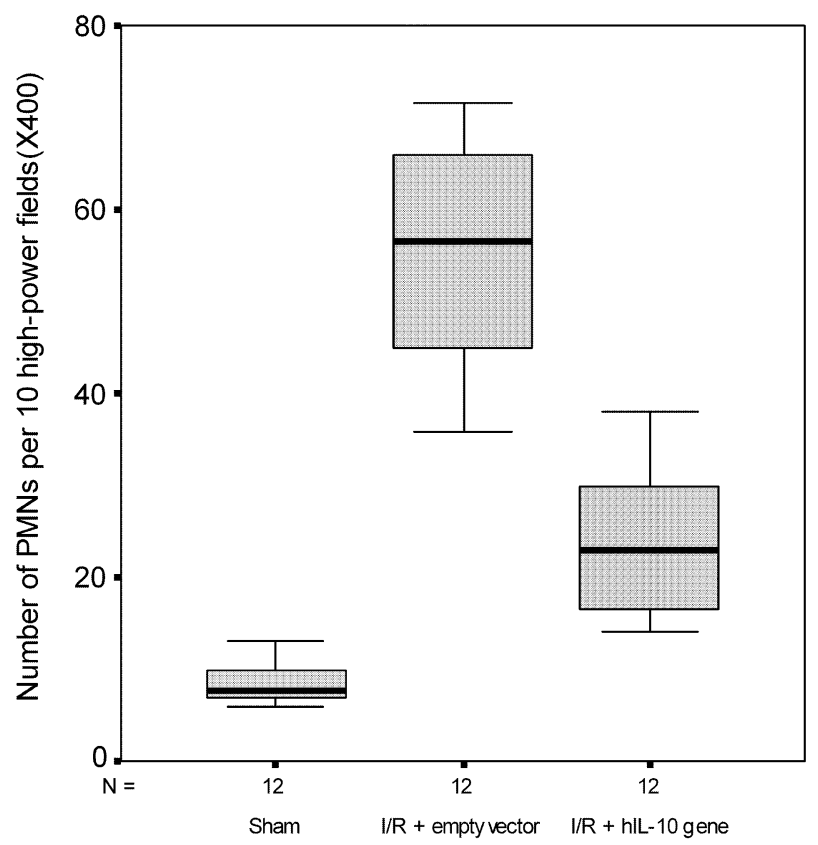

Fig. 6. Lung tissue neutrophil sequestration in groups. Lung tissue neutrophil count was significantly lower in IL-10 gene therapy group compared to empty plasmid DNA transferred group $(p=0.0001)$. 
significant $\left(\chi^{2}=30.76,2\right.$ d.f., $\left.p=0.0001\right)$. Similar differences were found among the groups regarding to MPO levels $\left(\chi^{2}=14.36,2\right.$ d.f., $\left.p=0.001\right)$. Neutrophil sequestration in the pulmonary tissue was significantly higher in animals that underwent empty vector transfered group than that in sham operated group $(54.62 \pm 3.42$ vs $8.36 \pm 1.96, p=$ $0.0001)$. Similarly, there was a significant increase in the MPO activity in pulmonary tissue after empty vector transfer compared to sham operation $(19.55 \pm 0.86$ vs $5.17 \pm 0.56, p=0.002)$. hIL-10 gene therapy significantly reduced the sequestration of neutrophils $(23.5 \pm 2.31, p=0.0001$ vs empty vector transferred group) and MPO activity $(8.96 \pm 1.01, p=0.002$ vs empty vector transferred group) in the pulmonary tissue. However, both neutrophil accumulation and MPO activity in hIL-10 gene therapy group were significantly higher than that of sham operated group $(p=0.009)$ (Figs. 5 and 6).

\section{Histopathological grading}

Light microscopic examination showed that reperfusion in empty vector injected group caused edema, hemorrhage, increased thickness of alveolar wall, and infiltration of inflammatory cells into alveolar spaces. These changes were less pronounced in hIL-10 pretreated group. The lung injury scores (median [range]) were $0(0), 2$ (1) and 4 (1) in sham, empty vector and hIL-10 pretreated groups, respectively $\left(\chi^{2}=15.8,2\right.$ d.f., $\left.p=0.001\right)$. hIL-10 gene therapy successfully reduced the histopathological severity of the lung injury.

\section{Survival}

Fig. 7 shows the 120-min survival pattern of mice submitted to ischemia of the SMA. There was $10 \%$ mortality rate by $60 \mathrm{~min}$. In plasmid DNA injected groups and $100 \%$ mortality rate was observed by $120 \mathrm{~min}$. In empty vector transferred group. In hIL-10 gene therapy group, $70 \%$

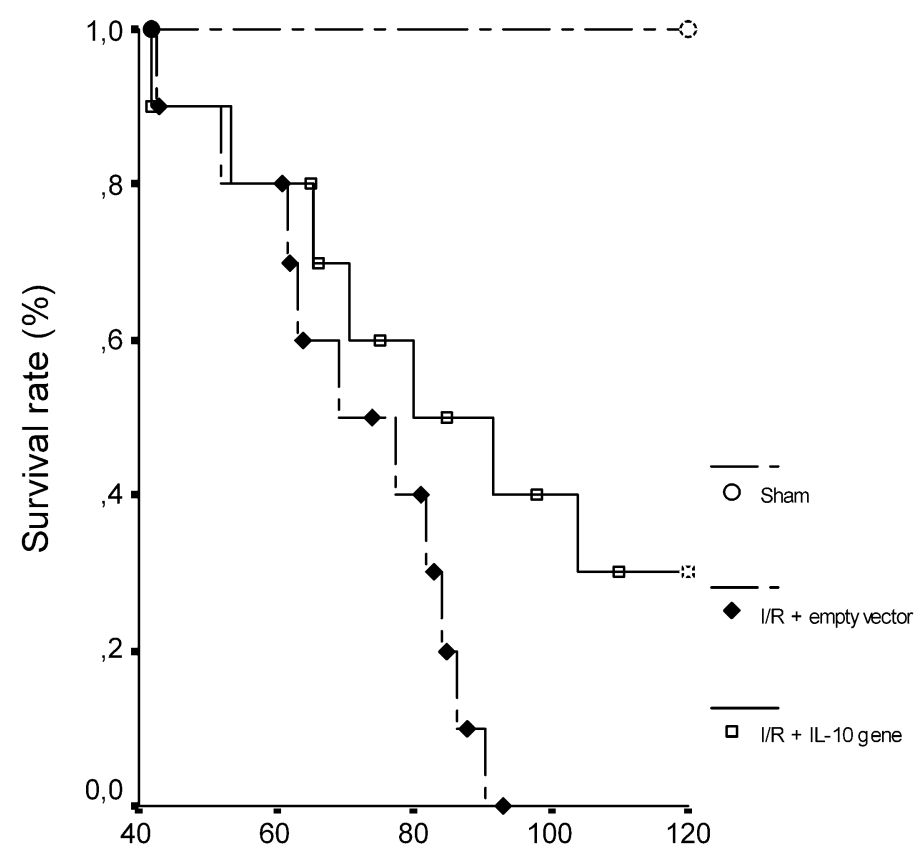

Time after reperfusion ( $\mathrm{min}$ )

Fig. 7. Reperfusion-associated increase in lethality of hIL-10 gene transferred mice submitted to ischemia of the SMA. Mice ( $n=10$ in each group) were anesthetized and submitted to ischemia of the SMA for 30 minutes. Tissue perfusion was then re-established and survival was monitored. Survival of the animals pretrated with hIL-10 encoding plasmid DNA was significantly more than nontreated group ( $p=0.0001)$. 
mortality rate was observed by $120 \mathrm{~min}(p=$ 0.0001 ) with a mean survival of $90.1 \mathrm{~min}$.

\section{Discussion}

Activated neutrophils are the principle cell type in $\mathrm{I} / \mathrm{R}$ induced local and remote organ injury and many functional activities of neutrophils are regulated by IL-10 (Moore et al. 1994; Tanita et al. 1999; de Perrot et al. 2003). A number of animal models have shown that endogenous production or administration of IL-10 may be beneficial in reducing organ injury as a consequence of the reduction in the number of neutrophils accumulating in these organs (Engles et al. 1997; Hess et al. 1997; Lane et al. 1997; Itano et al. 2000; Tagawa et al. 2002). Furthermore, IL-10 inhibits neutrophil interactions with endothelium in vivo models (Cassatella 1998). Due to these effects, we postulated that pre-ischemic hIL-10 overexpression would attenuate pulmonary tissue oxidative injury, in part by reducing pulmonary neutrophil infiltration. For this purpose, we proposed this technique of systemic liposomal plasmid DNA delivery in a mouse model of I/R-induced acute lung injury.

In our model, a single intraperitoneal injection of hIL-10 encoding plasmid DNA: liposome complexes before the induction of I/R lead to efficient gene transfer and provided effective tissue expression and plasma levels. We selected plasmid DNA encoding human IL-10 as a therapeutic gene because of its detectability in the circulation of animals by using commercially available ELISA kits. Liposomal gene transfer method is preferred regarding the study of Chun et al. (1999) that this type of gene expression was far more persistent than viral vector system. Also the systemic injection of DNA: liposome complexes into animals appears nontoxic. Moreover, liposomal complexes readily extravasate across vascular endothelial barriers in lung tissue and offer the advantage of transgene expression throughout the tissue (Zhu et al. 1993). However, slower onset of transgene expression to become effective and possible lipotoxicity for humans set a limit to the clinical application of this technique. So, regional administration into the selected tissue compart- ments or cell-type specific liposomal or viral gene delivery methods needs to be studied further.

In this study, reperfusion without hIL-10 overexpression after $60 \mathrm{~min}$ of mesenteric ischemia led to neutrophil accumulation and increased MPO activity, which is consistent with previous studies (Iglesias et al. 1998; Koksoy et al. 2000). We measured neutrophil accumulation both by determining MPO concentration within the lung and histopathological counting. Pre-treatment with hIL-10 encoding plasmid DNA was able to reduce MPO levels and neutrophil counts in the lungs after reperfusion. The significantly lower MPO activity and neutrophil counts in our experimental design could be attributed to the direct effect of IL-10 on neutrophil activation or may be mediated through a decrease in other inflammatory mediators. Regardless, hIL-10 encoding plasmid DNA pre-treatment may be beneficial in reducing remote organ injury by a reduction in the numbers of neutrophils accumulating in these organs.

IL-10 can be either protective or harmful in different experimental settings. Prior studies on selective intestinal-I/R injury mostly focused on effect of systemic administration of rIL-10 protein. In the study of Nussler et al. (2003), exogenously, single dose administration of IL-10 recombinant protein $5 \mathrm{~min}$ before the end of intestinal ischemia resulted in increased liver and small intestinal tissue destruction. In contrary, Lane et al. (1997) has shown that exogenously administered murine rIL-10 protein before and after reperfusion reduced the severity of local and systemic inflammation in intestinal I/R. Recently, lung transplantation studies with vectors carrying IL-10 gene reported reduced organ injury. In the study of Itano et al. (2000) intravenous adenoviral hIL-10 transfer into lung isografts attenuated subsequent reperfusion injury, improved gas exchange and decreased lung parenchymal neutrophil sequestration. In accordance with that study, Tagawa et al. (2002), using a similar rat lung transplantation model, introduced hIL-10 into the donor by endobronchial route 24 -hours before injury and showed the improvement of similar factors of pulmonary injury. It could be realised 
from these studies that site, dosage and timing of administration plays a role in biological activity of exogenous rIL-10 in inflammatory conditions. In the present study, the strong expression of hIL-10 protein in the lung tissue and the plasma hIL-10 concentration of $>10 \mathrm{ng} / \mathrm{ml}$ were observed at sacrifice. The observed survival benefit, at least in part, beyond the immediate period of $\mathrm{I} / \mathrm{R}$ injury could be attributed to the prolonged expression and prolonged abundance of the hIL-10 protein in tissue interstisium.

There are several methods to evaluate the degree of pulmonary edema in literature (Iglesias et al. 1998; Koike et al. 2000; Koksoy et al. 2001; Dowdall et al. 2002). Lung tissue wet/dry ratio and Evans blue dye concentration were used in the current study to assess the changes in the pulmonary microvascular permeability. In our model, Evans blue dye concentration and the lung tissue wet/dry ratio of animals sustaining mesenteric $\mathrm{I} / \mathrm{R}$ were significantly higher than that of controls and, a finding consistent with previous studies (Koksoy et al. 2001). The lung edema expressed by both increased Evans blue dye concentration and tissue wet/dry ratio was significantly reduced with the use of pre-ischemic IL-10 gene overexpression. Also these findings were grossly manifested in the lung injury scores that showed diminished perivascular edema and alveolar destruction. Although the detailed mechanisms in which pre-ischemic hIL-10 gene therapy attenuates the development of $\mathrm{I} / \mathrm{R}$ related lung edema were not completely assessed in our study, the influence of IL-10 on microvascular permeability appears to be related with neutrophil-endothelial interactions and migration. Previous studies have shown that increased capillary permeability following mesenteric I/R occurs synchronously in both the intestine and the lung that correlates with the increase in the appearance of activated neutrophils in the circulation (Kuzu et al. 2002). Similar correlation between pulmonary tissue microvascular permeability and the activated neutrophil count were encountered in our study. Moreover, synchronous decrease in the number of activated neutrophils and the amount of pulmonary microvascular permeability in hIL-10 treated group also supports the idea that neutrophils have a major role in the development of pulmonary microvascular leakage. Koksoy et al. (2000) also shown that endothelial and smooth muscle dysfunction, pulmonary vasoconstriction and a damaged microvascular barrier, contributes to the pulmonary edema after intestinal I/R. The effects of IL-10 in this context needs to be clarified and warrants further studies.

We conclude that pre-ischemic IL-10 gene therapy has a beneficial effect on lung injury after selective intestinal ischemia. The results suggest the therapeutic potential of systemic gene transfer as an effective strategy against remote organ dysfunction after intestinal ischemia and further studies would be productive.

\section{References}

Abraham, E. (2003) Neutrophils and acute lung injury. Crit. Care Med., 31, 95-199.

Aytekin, F.O., Tekin, K., Kabay, B., Erdem, E., Guney, Y., Firat, P., Sungurtekin, U., Kaya, S.O. \& Ozden, A. (2005) Antithrombin III attenuates pulmonary tissue injury caused by mesenteric ischemia-reperfusion. Am. J. Surg., 189, 161-166.

Barbara, G., Zing, Z., Hogaboam, C.M., Gauldie, J. \& Collins, S.M. (2000) IL-10 gene transfer prevents experimental colitis in rats. Gut, 46, 344-349.

Cassatella, M.A. (1998) The neutrophil:one of the cellular targets of interleukin-10. Int. J. Clin. Lab. Res., 28, 148-161.

Chernoff, A.E., Granowitz, E.V., Shapiro, L., Vannier, E., Lonnemann, G., Angel, J.B., Kennedy, J.S., Rabson, A.R., Wolff, S.M. \& Dinarello, C.A. (1995) A randomized, controlled trial of IL-10 in humans. Inhibition of inflammatory cytokine production and immune responses. J. Immunol., 154, 5492-5499.

Chun, S., Dahessia, M., Lee, S. \& Rouse, B.T. (1999) Immune modulation by IL-10 gene transfer via viral vector and plasmid DNA:Implication for gene therapy. Cell. Immunol., 194, 194-204.

de Perrot, M., Liu, M., Waddell, T.K. \& Keshavjee, S. (2003) Ischemia-reperfusion-induced lung injury. Am. J. Respir. Crit. Care Med., 167, 490-511.

Dowdall, J.F., Winter, D.C. \& Bouchier-Hayes, D.J. (2002) Inosine modulates gut barrier dysfunction and end organ damage in a model of ischemia-reperfusion injury. J. Surg. Res., 108, 61-68.

Engles, R.E., Huber, T.S., Zander, D.S., Hess, P.J., Welborn, M.B., Moldawer, L.L. \& Seeger, J.M. (1997) Exogeneous human recombinant IL-10 attenuates hindlimb ischemia reperfusion injury. J. Surg. Res., 69, 425-428.

Fiorentino, D.F., Zlotnik, A., Mosmann, T.R., Howard, M. \& O'Garra, A. (1991) IL-10 inhibits cytokine production by activated macrophages. J. Immunol., 147, 3815-3819.

Hess, P.J., Seeger, J.M., Huber, T.S., Welborn, M.B., Martin, T.D., Harward, T.R., Deschek, S., Edwards, P.D., Solorzano, C.C., Copeland, E.M. \& Moldawer, L.L. (1997) 
Exogenously administered IL-10 decreases pulmonary neutrophil infiltration in a tumor necrosis factor-dependent murine model of acute visceral ischemia. J. Vasc. Surg., 26,113-118.

Iglesias, J.L., LaNoue, J.L., Rogers, T.E., Inman, L. \& Turnage, R.H. (1998) Physiologic basis of pulmonary edema during intestinal repefusion. J. Surg. Res., 80, 156-163.

Itano, H., Zhang, W., Ritter, J.H., McCarthy, T.J., Mohanakumar, T. \& Patterson, G.A. (2000) Adenovirusmediated gene transfer of human interleukin 10 ameliorates reperfusion injury of rat lung isografts. J. Thorac. Cardiovasc. Surg., 120, 947-956.

Koike, K., Moore, E.E., Moore, F.A., Read, R.A., Carl, V.S. \& Banerjee, A. (1994) Gut ischemia/reperfusion produces lung injury independent of endotoxin. Crit. Care Med., 22, 1438-1444.

Koike, K., Yamamoto, Y., Hori, Y. \& Ono, T. (2000) Group II phospholipase A2 mediates lung injury in intestinal ischemia-reperfusion. Ann. Surg., 232, 90-97.

Koksoy, C., Kuzu, M.A., Ergun, H., Demirpence, E. \& Zulfikaroglu, B. (2000) Intestinal ischemia and reperfusion impairs vasomotor functions of pulmonary vascular bed. Ann. Surg., 231, 105-111.

Koksoy, C., Kuzu, M.A., Kuzu, I., Ergun, H. \& Gurhan, I. (2001) Role of tumour necrosis factor in lung injury caused by intestinal ischaemia-reperfusion. Br. J. Surg., 88, 464-468.

Kuzu, M.A., Koksoy, C., Kuzu, I., Gurhan, I., Ergun, H. \& Demirpence, E. (2002) Role of integrins and intracellular adhesion molecule-1 in lung injury after intestinal ischemia-reperfusion. Am. J. Surg., 183, 70-74.

Lane, J.S., Todd, K.E., Lewis, M.P., Gloor, B., Ashley, S.W., Reber, H.A., McFadden, D.W. \& Chandler, C.F. (1997) Interleukin 10 reduces the systemic inflammatory response in a murine model of intestinal ischemia/reperfusion. Surgery, 122, 288-294.

Li, L., Elliot, J.F. \& Mosmann, J.R. (1994) IL-10 inhibits cytokine production, vascular leakage and swelling during $\mathrm{T}$ helper 1 cell induced delayed type hypersensitivity. J. Immunol., 153, 3967-3978.

Lucchesi, B.R. (1994) Complement, neutrophils and free radicals: mediators of reperfusion injury. Arzneimittelforschung, 44, 420-432.

McMillen, M.A., Huribal, M. \& Sumpio, B. (1993) Common pathway of endothelial-leukocyte interaction in shock, ischemia, and reperfusion. Am. J. Surg., 166, 557-562.

Moore, E.E., Moore, F.A., Franciose, R.J., Kim, F.J., Biffl, W.L. \& Banerjee, A. (1994) The postischemic gut serves as a priming bed for circulating neutrophils that provoke multiple organ failure. J. Trauma, 37, 881-887.

Moore, K.W., de Waal Malefyt, R., Coffman, R.L. \& O'Garra, A. (2001) Interleukin-10 and the interleukin-10 receptor.
Annu. Rev. Immunol., 19, 683-765.

Morrison, D., Foss, D.L. \& Murtaugh, M.P. (2000) IL-10 gene therapy-mediated amelioration of bacterial pneumonia. Infect. Immun., 30, 4752-4758.

Nishina, K., Mikawa, K., Takao, Y., Maekawa, N., Shiga, M. \& Obara, H. (1997) ONO-5046, an elastase inhibitor, attenuates endotoxin-induced acute lung injury in rabbits. Anesth. Analg., 84, 1097-1103.

Nussler, N.C., Muller, A.R., Weidenbach, H., Vergopoulos, A., Platz, K.P., Volk, H.D., Neuhaus, P. \& Nussler, A.K. (2003) IL-10 increases tissue injury after selective intestinal ischemia/reperfusion. Ann. Surg., 238, 49-58.

Ogawa, M. (1996) Mechanism of the development of organ failure following surgical insult: the second attack theory. Clin. Int. Care, 7, 34-38.

Sakuma, T., Hida, M., Nambu, Y., Osanai, K., Toga, H., Takahashi, K., Ohya, N., Inoue, M. \& Watanabe, Y. (2001) Beta1-adrenergic agonist is a potent stimulator of alveolar fluid clearance in hyperoxic rat lungs. Jpn. J. Pharmacol., 85, 161-166.

Schmelling, D.J., Caty, M.G., Oldham, K.T., Guice, K.S. \& Hinshaw, D.B. (1989) Evidence for neutrophil-related acute lung injury after intestinal ischemia-reperfusion. Surgery, 106, 195-202.

Sisley, A.C., Desay, T., Harig, J.M. \& Gewertz, B.L. (1994) Neutrophil depletion attenuates human intestinal reperfusion injury. J. Surg. Res., 57, 192-196.

Tagawa, T., Suda, T., Daddi, N., Kozower, B.D., Kanaan, S.A., Mohanakumar, T. \& Patterson, G.A. (2002) Low-dose endobronchial gene transfer to ameliorate lung graft ischemiareperfusion injury. J. Thorac. Cardiovasc. Surg., 123, 795-802.

Tanita, T., Song, C., Kubo, H., Ono, S., Sagawa, M., Sato, M., Matsumura, Y., Kondo, T. \& Fujimura, S. (1999) Stimulated neutrophils evoke signal transduction to increase vascular permeability in rat lungs. Tohoku J. Exp. Med., 189, 213-225.

Takakuwa, T., Endo, S., Shirakura, Y., Yokoyama, M., Tamatani, M., Tohyama, M., Aozasa, K. \& Inada, K. (2000) Interleukin-10 gene transfer improves the survival rate of mice inoculated with E. coli. Crit. Care Med., 28, 2685-2689.

Yang, Z., Zingarelli, B. \& Szobo, C. (2000) Crucial role of endogenous IL-10 production in myocardial ischemia-reperfusion injury. Circulation, 101, 1019-1026.

Yoshidome, H., Kato, A., Edwards, M.J. \& Lentsch, A.B. (1999) Interleukin 10 inhibits pulmonary $\mathrm{NF}_{-} \mathrm{B}$ activation and lung injury induced by hepatic ischemia reperfusion. Am.J. Phisiol., 277, 919-923.

Zhu, N., Liggitt, D., Liu, Y. \& Debs, R. (1993) Systemic gene expression after intravenous DNA delivery into adult mice. Science, 261, 209-211. 